\title{
Endorsement by Central European experts of the revised ESCEO algorithm for the management of knee osteoarthritis
}

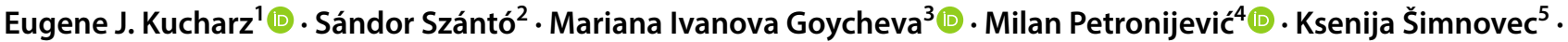 \\ Marcin Domżalski ${ }^{6} \cdot$ Luca Gallelli $^{7}$ (i) $\cdot$ Zdravko Kamenov $^{8}$. Jerzy Konstantynowicz ${ }^{9}$ (i) Goran Radunović ${ }^{10}$ (1) . \\ Boris Šteňo ${ }^{11}$ (1) $\cdot$ Rumen Stoilov $^{3}$ (1) $\cdot$ Rasto Stok $^{12} \cdot$ Radovan Vrana $^{13}$ (1) $\cdot$ Olivier Bruyère $^{14,15}$ (1) Cyrus Cooper ${ }^{15,16,17 \text { (1) }}$. \\ Jean-Yves Reginster ${ }^{14,15,18}$
}

Received: 13 April 2019 / Accepted: 21 May 2019 / Published online: 25 May 2019

(c) The Author(s) 2019

\begin{abstract}
Osteoarthritis (OA) is characterized by deterioration of the joints and associated with considerable pain and disability. OA is a chronic disease that requires intervention with both non-pharmacological and pharmacological treatment modalities and, inevitably, disease progression may necessitate successive treatments throughout the course of the disease. There is increasing data on the shortfalls of current pharmacological treatment of OA, and safety concerns associated with analgesic therapy use in OA arising from increasing evidence of gastrointestinal, cardiovascular, hepatic and renal adverse events with paracetamol and non-steroidal anti-inflammatory drugs (NSAIDs). Consequently, symptomatic slow-acting drugs for OA (SYSADOAs) may now be considered as a first-line treatment for knee OA, with a particular emphasis placed on the outstanding benefit: risk ratio of pharmaceutical-grade glucosamine and chondroitin sulfate formulations. In this short communication we review recent publications concerned with the safety of paracetamol, NSAIDs and SYSADOAs. Greater understanding of the benefits and limitations of current medications will lead to better disease management in OA. Furthermore, adherence to guideline recommendations across Europe and internationally, such as those from the European Society for Clinical and Economic Aspects of Osteoporosis, Osteoarthritis and Musculoskeletal Diseases (ESCEO), will promote evidence-based medicine and patient-centric care, ultimately leading to greater physician and patient satisfaction.
\end{abstract}

Keywords NSAID $\cdot$ Osteoarthritis $\cdot$ Paracetamol $\cdot$ Safety $\cdot$ SYSADOA

$\begin{array}{ll}\text { Abbreviations } \\ \text { ASU } & \text { Avocado soybean unsaponifiables } \\ \text { COX-2 } & \text { Cyclo-oxygenase-2 } \\ \text { CS } & \text { Chondroitin sulfate } \\ \text { NSAID } & \text { Non-steroidal anti-inflammatory drug } \\ \text { OA } & \text { Osteoarthritis } \\ \text { pCGS } & \text { Prescription crystalline glucosamine sulfate } \\ \text { SYSADOA } & \text { Symptomatic slow-acting drugs for } \\ & \text { osteoarthritis }\end{array}$

Jean-Yves Reginster

jyreginster@uliege.be

Extended author information available on the last page of the article

\section{Introduction}

Osteoarthritis (OA) is a long-term chronic disease characterized by deterioration in joints resulting in pain and stiffness and impaired movement. OA is strongly, but not exclusively, associated with aging, and most-commonly affects the knees, hips, and hands. Across Europe, age-standardized self-reported, doctor diagnosed, OA ranges from $2.8 \%$ in Romania to $18.3 \%$ in Hungary, and globally it is estimated that 1 in 10 of the population aged 60 years or older have significant clinical problems that can be attributed to OA [1].

The European Society for Clinical and Economic Aspects of Osteoporosis, Osteoarthritis and Musculoskeletal Diseases (ESCEO) published recommendations for the management of knee OA as a stepwise treatment algorithm to guide physicians through progressive, logical steps [2]. These guidelines were well-received internationally and are used widely across Europe [3]. The ESCEO guidelines include a core set comprising the education of patients with 
BASIC PRINCIPLE AND CORE SET

Combination of treatment modalities, including non-pharmacological and pharmacological therapies is strongly recommended

Core set: - Information/Education

- Weight loss if overweight

- Exercise program (i.e. aerobic, strengthening, or resistance exercises)

STEP 1: Background treatment

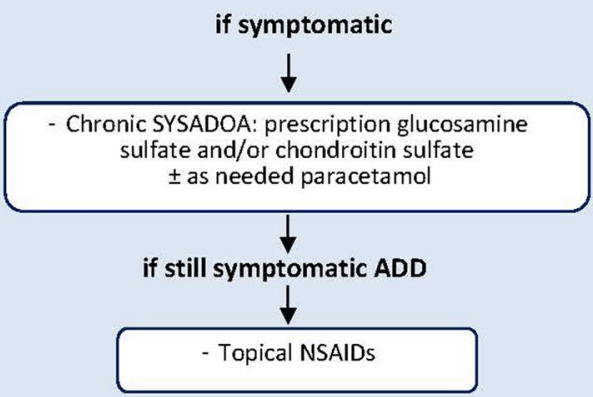

STEP 2: Advanced pharmacological management in the persistent symptomatic patient

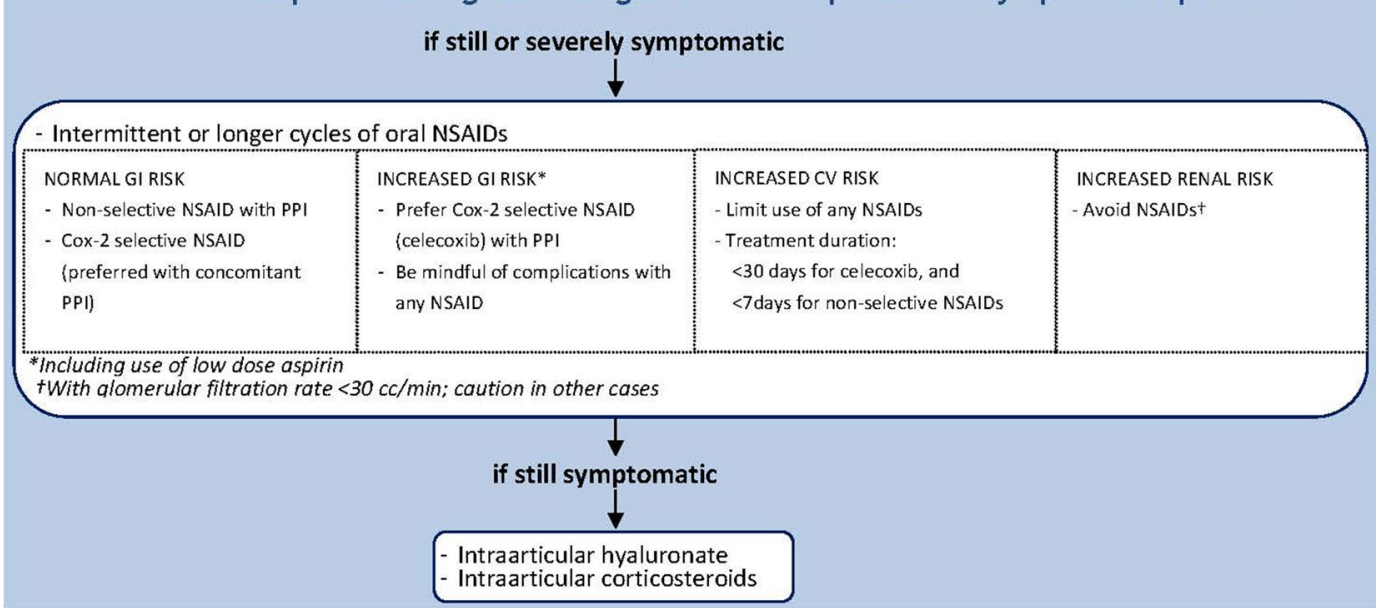

STEP 3: Last pharmacological attempts

$\downarrow$
- Short-term weak opioids
- Duloxetine

STEP 4: End-stage disease management and surgery

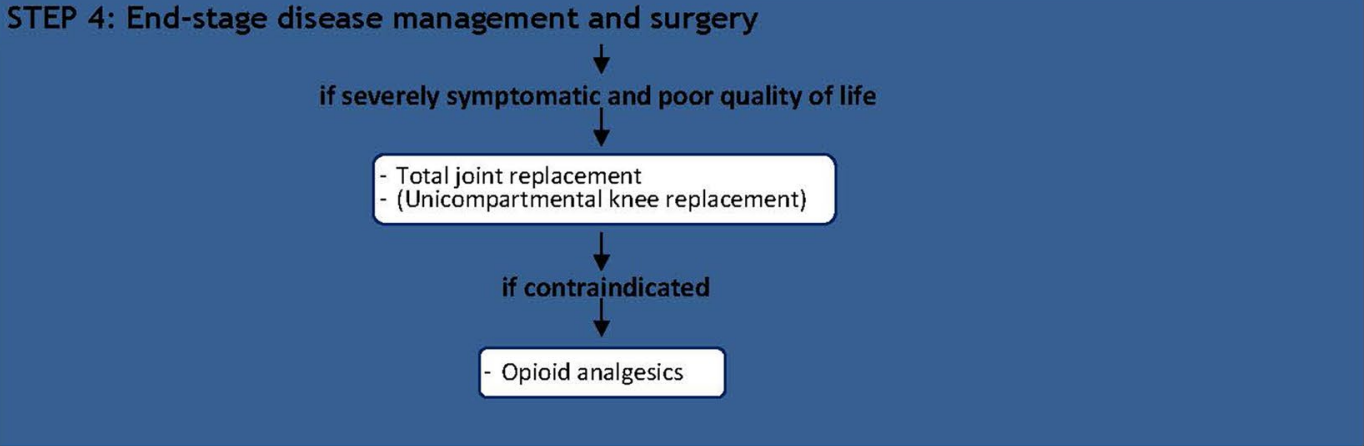

Opioid analgesics
Referral to physical therapist for: if needed

(to control malalignment)
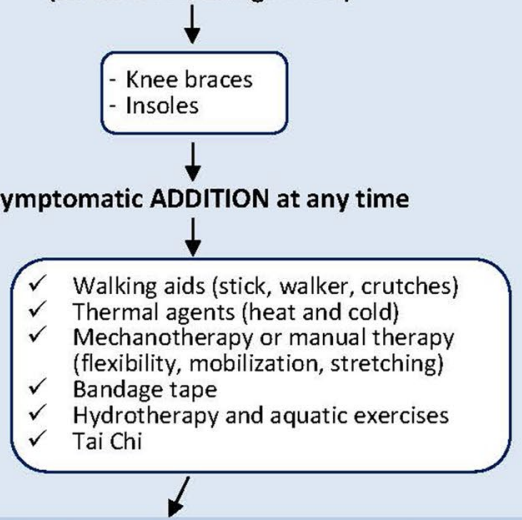

symptomatic ADDITION at any time

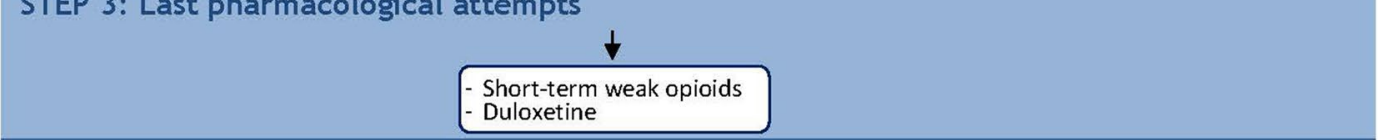


४Fig. 1 Updated ESCEO stepwise treatment algorithm for knee osteoarthritis. $C O X-2$ cyclooxygenase-2, $C S$ chondroitin sulfate, $C V$ cardiovascular, GI gastrointestinal, $G S$ glucosamine sulfate, $I A$ intra-articular, NSAID non-steroidal anti-inflammatory drug, $P P I$ proton pump inhibitor, SYSADOA symptomatic slow-acting drugs in osteoarthritis, $O A$ osteoarthritis Reprinted from Semin Arthritis Rheum 2019; April 30 online. https://doi.org/10.1016/j.semarthrit.2019.04.008. Bruyère $\mathrm{O}$, et al. An updated algorithm recommendation for the management of knee osteoarthritis from the European Society for Clinical and Economic Aspects of Osteoporosis, Osteoarthritis and Musculoskeletal Diseases (ESCEO), Copyright 2019, with permission from Elsevier

disease information, recommended weight loss if overweight and an exercise program, along with a combination of treatment modalities including non-pharmacological and pharmacological interventions [2]. Since publication of the 2014 algorithm, considerable new evidence has been published particularly regarding the safety of many medications commonly used to treat OA. In preparation for a guideline update, a full literature search on all interventions for knee OA covering the period from 2014 through to September 30, 2018 was performed. In addition, the ESCEO identified a need for comprehensive safety data on anti-OA medications, and commissioned several safety meta-analyses on different classes of anti-OA medications, including symptomatic slow-acting drugs for osteoarthritis (SYSADOAs) and cyclooxygenase-2 (COX-2) inhibitors. The results of these safety meta-analyses were included alongside the literature search results in the analysis and formulation of revised guidelines, which are summarized in the modified treatment algorithm (Fig. 1) [4]. While it is recognized that OA management practices can vary slightly between "Western" and "Central" Europe, the ESCEO guidelines, which were originally drafted by a panel of physicians mainly from Western Europe, are also endorsed by the Central European authors here. Our article provides a summary of the new safety data identified for selected OA medications, namely paracetamol, SYSADOAs, and non-steroidal anti-inflammatory drugs (NSAIDs) alongside recommendations for the appropriate use of these medications in OA.

\section{Paracetamol}

Paracetamol (acetaminophen) is widely used as rescue analgesia for OA, despite having only minimal effect on pain (effect size [ES] 0.14, 95\% CI 0.05-0.23) and no significant effect on stiffness and physical function in patients with knee OA [5]. Recent concerns over the safety profile of paracetamol raise questions over its routine chronic use, due to increasing evidence of gastrointestinal (GI), cardiovascular (CV), and renal adverse events (AEs), and increased mortality risk associated with paracetamol use [6]. A systematic literature review of observational studies identified a considerable degree of toxicity with paracetamol, especially at the upper end of standard analgesic doses (up to $4 \mathrm{~g}$ /day) [6]. Eight cohort studies included in the review investigated $\geq 1$ of the AEs of interest with oral doses of paracetamol of $0.5-1.0 \mathrm{~g}$ every $4-6 \mathrm{~h}$ to a maximum $4.0 \mathrm{~g} /$ day. Two of the studies reported on mortality, of which one reported a dose-response increase in all-cause mortality and rate of gastrointestinal AEs or bleeds based upon low to high medication possession ratio (measured by repeat prescription frequency), and the other study reported an increase in standardized mortality ratio for patients prescribed paracetamol compared with those not prescribed paracetamol, regardless of specific cause of death, with a nearly doubled overall death rate [6]. Four studies included in the analysis showed a dose-response relationship between paracetamol use and risk of CV AEs, and three studies reported an increased risk of renal AEs with paracetamol [6]. Reports of hepatotoxicity and acute liver failure associated with chronic paracetamol dosing are a further cause of concern with widespread, unrestricted paracetamol use [7].

Consequently, when analgesic benefit is uncertain and with increasing safety issues, more careful consideration of paracetamol use is required. The ESCEO algorithm recommends that paracetamol be used as short-term rescue analgesia only (dose $\leq 3 \mathrm{~g} /$ day) given on top of a background of SYSADOAs [4].

\section{SYSADOAs}

There are many different agents in the class of SYSADOAs including glucosamine, chondroitin, diacerein, and avocado soybean unsaponifiables (ASU), and confusion may arise over appropriate prescribing and use of this class of agents. Multiple formulations of these agents are available, both as prescription-grade products and nutritional supplements. However, while all preparations may claim to deliver a therapeutic level of the active agent, not all are supported by clinical evidence $[8,9]$. Only the prescription crystalline glucosamine sulfate (pCGS) is shown to deliver consistently high glucosamine bioavailability and plasma concentration in humans, which corresponds to demonstrated clinical efficacy [10-12]. Conversely, glucosamine hydrochloride and non-characterized glucosamine sulfate products are repeatedly demonstrated as ineffective in OA [12-14]. Similarly, only pharmaceutical-grade chondroitin sulfate (CS) has been evaluated for purity, content and physiochemical parameters [9], and clinical evidence supports only pharmaceuticalgrade CS [15].

Both glucosamine and CS can be considered as safe treatments for patients with OA. A recent systematic review and meta-analysis found no statistically significant increase in odds between glucosamine or CS, each compared with 
placebo, for any system organ class (SOC)-related disorders including: GI, cardiac, vascular, nervous system, skin and subcutaneous tissue, musculoskeletal and connective tissue, and disorders of the renal and urinary systems [16]. In addition, no difference in odds for severe and serious AEs, and for withdrawals due to AEs was found for glucosamine or CS versus placebo. Similarly, no safety issues were found with ASU, although only studies that included a single proprietary ASU product (Piascledine ${ }^{\circledR}$ ) and allowed concomitant rescue anti-OA medications qualified for the analysis. Consequently, the safety of ASU as a whole requires further investigation.

Diacerein has a small beneficial effect on OA pain; however, the safety of diacerein has been called into question. In a meta-analysis, the odds of any $\mathrm{AE}$ with diacerein was more than twice that of placebo (odds ratio [OR] 2.22, 95\% CI 1.58, 3.13) [16]. This was largely due to increased odds of GI AEs with diacerein versus placebo (OR 2.85, 95\% CI $2.02,4.04$ ), of which diarrhea, abdominal pain, soft stools, and colitis were frequently reported, and a high increase in odds of renal and urinary disorders with diacerein (OR 3.42 ; 95\% CI 2.36, 4.96), urine discoloration being the most reported effect. A significant increase in odds of dermatological disorders was found with diacerein versus placebo (OR 2.18, 95\% CI 1.40, 3.42), specifically eczema, rash, pruritus, and urticaria.

Thus, among the SYSADOA products available, pharmaceutical-grade pCGS and CS are strongly recommended by the ESCEO as first-line SYSADOAs, for which the evidence base is unequivocal [4]. Other SYSADOAs (diacerein and ASU) may be used as alternative step 1 background therapy; however, the evidence for their efficacy and safety is scarcer than that of CS and pCGS.

\section{NSAIDs}

NSAIDs are one of the most widely used drugs in OA. Topical NSAIDs may be added to the treatment regimen in Step 1 therapy if the patient is still symptomatic, and may be used in preference to oral NSAIDs particularly in patients aged $\geq 75$ years as they have similar efficacy to the oral medications in reducing pain (ES $0.44,95 \%$ CI 0.27 , 0.62 ) with a reduced risk of systemic AEs [4]. An increase in mild local skin reactions is observed with topical NSAIDs although this may be product-specific, and is notably higher with diclofenac [17]. Topical NSAIDs are recommended as add-on analgesia in Step 1 for patients who are still symptomatic, and prior to the use of oral NSAIDs [4].

Oral NSAIDs are included as step 2 treatment in the ESCEO algorithm for management of knee OA, in those with moderate to severe pain, and those unresponsive to Step 1 interventions [4]. Oral NSAIDs have a small to moderate effect on pain in short-term studies (ES 0.29, 95\% CI 0.22, $0.35)$ [5]. Oral NSAIDs have been associated with wideranging AEs affecting, amongst others, the GI, $\mathrm{CV}$ and renal systems. GI toxicity is found with all NSAIDs which may be of particular concern when treating older patients with OA. All NSAID regimens, including non-selective (ns)-NSAIDs and COX-2-selective NSAIDs, are found to increase upper GI complications (COX-2 inhibitors Rate ratio [RR] 1.81, 95\% CI 1.17,2.81; diclofenac RR 1.89, 95\% CI 1.16, 3.09; ibuprofen RR 3.97, 95\% CI 2.22, 7.10; and naproxen RR $4.22,95 \%$ CI 2.71, 6.56) [18]. Gastric AEs associated with nsNSAIDs may be reduced by taking a concomitant gastroprotective agent (proton pump inhibitor), although intestinal AEs are not ameliorated [19].

$\mathrm{CV}$ risk exists for both nsNSAIDs and COX-2 inhibitors alike, and thus $\mathrm{CV}$ toxic effects may result from differences in physiochemical properties $[18,20]$. A meta-analysis of 26 randomized controlled trials compared the incidence of $\mathrm{CV}$ endpoints between different NSAIDs finding the highest risk with rofecoxib among all NSAIDs [20]. Conversely, celecoxib has lower CV toxicity [21], and among nsNSAIDs naproxen has the lowest CV toxicity [18].

The absolute risk of myocardial infarction (MI) associated with NSAID use is estimated to be about $0.5-1 \%$ per year [22]; although small, the absolute risk is increased with all NSAIDs. In a recent safety meta-analysis, COX-2 inhibitors were associated with an increased risk of heart failure and edema (RR 1.68, 95\% CI 1.22, 2.31) compared with placebo, which remained significant even when rofecoxib was removed from the analysis (RR 1.67, 95\% CI 1.21, 2.29) [23]. While NSAIDs use overall is associated with only a small, but insignificant risk of hemorrhagic stroke, an elevated risk of hemorrhagic stroke is found with diclofenac (RR 1.27, 95\% CI, 1.02, 1.59) and meloxicam (RR 1.27, 95\% CI, 1.08, 1.50) [24].

All NSAIDs have the potential to induce acute kidney injury (AKI) and the risk of AKI is particularly high in the first 30 days after initiation of therapy. NSAID users have a threefold greater risk of developing clinical AKI compared with non-NSAID users in the general population and OA patients with co-morbid conditions including hypertension, heart failure and diabetes mellitus are at increased risk [25]. Oral NSAIDs may be partly responsible for the excess mortality seen in patients with OA and should be used judiciously in OA due to safety considerations.

Consequently, the ESCEO guidelines recommend that oral NSAID use be limited to the lowest effective dose for the shortest time necessary to control symptoms, either intermittently or in longer cycles rather than in chronic use [4]. 


\section{Discussion}

Greater understanding of the benefits and limitations of current medications will lead to better disease management in OA. Data is accumulating on the shortfalls of current pharmacological treatment of OA, highlighted by issues of safety arising with analgesic therapies including paracetamol and NSAIDs. Due to the safety issues with paracetamol, SYSADOAs are now a first-line treatment for knee $\mathrm{OA}$, with a particular emphasis placed on the outstanding benefit: risk ratio of pharmaceutical-grade pCGS and CS. As a step 2 treatment in OA patients who are unresponsive, or have moderate-severe pain, oral NSAIDs may offer good analgesia in the short-term; however, chronic use is not recommended due to GI, CV and renal toxicity. As a last resort, pharmacotherapy with weak opioids may be considered, although a recent report of association of opioids with increased all-cause mortality among OA patients requires further investigation [26].

Non-pharmacological interventions are often underutilized, and more could be achieved through appropriate application of the core set principles (education, weight management and exercise) and the combination of nonpharmacological and pharmacological treatment modalities throughout the treatment plan. Patient, physician and pharmacist education is an essential element of successful OA management, which may be achieved through programs that promote knowledge and understanding within the medical profession through medical societies, and in the wider community through patient societies. Finally, adherence to guideline recommendations, such as the updated ESCEO treatment algorithm for knee OA, will promote evidencebased medicine and patient-centric care, ultimately leading to greater physician and patient satisfaction across Europe and internationally.

Acknowledgements This paper is written on behalf of the European Society for Clinical and Economic Aspects of Osteoporosis, Osteoarthritis and Musculoskeletal Diseases (ESCEO) following a working group meeting held in Krakow, Poland, April 19, 2018. The paper was drafted as a result of data presentations given by the authors (EK, SS, JYR, CC, OB, MIG, MP and KS) and discussions held within the group. The authors would like to express their most sincere gratitude to Dr Lisa Buttle for her invaluable help with the manuscript preparation. Dr Lisa Buttle was entirely funded by the ESCEO asbl, Belgium.

Funding The working group meeting was entirely funded by the ESCEO, a Belgian not-for-profit organization. The ESCEO receives unrestricted educational grants, to support its educational and scientific activities, from Non-Governmental Organizations, not-for-profit organizations, non-commercial and corporate partners. The choice of topics, participants, content and agenda of the working groups as well as the writing, editing, submission and reviewing of the manuscript are under the sole responsibility of the ESCEO, without any influence from third parties.

\section{Compliance with ethical standards}

Conflict of interest Eugene J. Kucharz reports royalties for lecturing and expert fee from the following companies: AbbVie, Berlin Chemie, Biogen, Celgene, Egis, Eli Lilly Polska, MSD, Novartis, Pfizer, Polpharma, Roche, Sandoz, UCB Biopharma, outside the submitted work. S. Szanto reports personal fees from Roche, personal fees from MSD, personal fees and non-financial support from Abbvie, grants and personal fees from Pfizer, personal fees from Novartis, personal fees from KRKA, personal fees from Sager Pharma, personal fees and nonfinancial support from Mylan, outside of the submitted work; O. Bruyère reports grants from Biophytis, IBSA, MEDA, Servier, SMB, and Theramex, outside the submitted work. C. Cooper has received lecture fees and honoraria from Amgen, Danone, Eli Lilly, GSK, Kyowa Kirin, Medtronic, Merck, Nestlé, Novartis, Pfizer, Roche, Servier, Shire, Takeda and UCB outside of the submitted work. J-Y. Reginster reports grants from ELI LILLY, grants and personal fees from SERVIER, grants and personal fees from MEDA, grants and personal fees from CNIEL, grants and personal fees from IBSA GENEVRIER, personal fees from RADIUS HEALTH, grants and personal fees from PIERRE FABRE, personal fees from DAIRY RESEARCH COUNCIL, outside of the submitted work. J. Konstantynowicz reports non-financial support from Takeda/Shire and Mylan (travel and conference fee), outside of the submitted work. M. Ivanova Goycheva reports payment for lectures from Abbvie, Pfizer, Novartis, UCB, Mylan, Amgen, outside of the submitted work. Z. Kamenov reports lecturing fees, personal fees, and expert fees from Boehringer, Astra Zeneca, Mundipharma, NovoNordisk, Sanofi, Eli Lilly, Berlin Chemie, MSD, Novartis, Sandoz, Merck, MEDA, Mylan, Servier, outside the submitted work. M. Petronijevic reports non-financial support from Takeda/Shire, and non-financial support from Mylan, outside of the submitted work. R. Stoilov reports payment for lectures from Pfizer, Abbvie, UCB, MSD, Novartis, Mylan, Amgen, outside of the submitted work. M. Domzalski, G. Radunovic, R. Vrana, R. Stok, K. Simnovec, B. Steno, and L. Gallelli declare that they have no conflicts of interest.

Ethical approval All authors meet the ICMJE criteria for authorship for this manuscript, take responsibility for the integrity of the work as a whole, and have given final approval to the version to be published.

Open Access This article is distributed under the terms of the Creative Commons Attribution 4.0 International License (http://creativeco mmons.org/licenses/by/4.0/), which permits unrestricted use, distribution, and reproduction in any medium, provided you give appropriate credit to the original author(s) and the source, provide a link to the Creative Commons license, and indicate if changes were made.

\section{References}

1. EUMUSC (2012) Musculoskeletal health in Europe report v5.0. www.Eumusc.Net. Accessed 19 Feb 2019

2. Bruyere O, Cooper C, Pelletier JP, Branco J, Brandi ML, Guillemin $\mathrm{F}$ et al (2014) An algorithm recommendation for the management of knee osteoarthritis in Europe and internationally: a report from a task force of the European Society for Clinical and Economic Aspects of Osteoporosis and Osteoarthritis (ESCEO). Semin Arthritis Rheum 44(3):253-263. https://doi.org/10.1016/j. semarthrit.2014.05.014

3. Bruyere O, Cooper C, Cutolo M, Reginster JY (2017) International endorsement of the ESCEO algorithm for management of knee osteoarthritis in clinical practice. Semin Arthritis Rheum 47(2):e10. https://doi.org/10.1016/j.semarthrit.2017.07.002 
4. Bruyère $\mathrm{O}$, Honvo $\mathrm{G}$, Veronese $\mathrm{N}$, Arden $\mathrm{NK}$, Branco J, Curtis EM et al (2019) An updated algorithm recommendation for the management of knee osteoarthritis from the European Society for Clinical and Economic Aspects of Osteoporosis, Osteoarthritis and Musculoskeletal Diseases (ESCEO). Semin Arthritis Rheum. https://doi.org/10.1016/j.semarthrit.2019.04.008

5. Zhang W, Nuki G, Moskowitz RW, Abramson S, Altman RD, Arden NK et al (2010) OARSI recommendations for the management of hip and knee osteoarthritis. Part III: changes in evidence following systematic cumulative update of research published through january 2009. Osteoarthr Cartil 18(4):476-499. https:// doi.org/10.1016/j.joca.2010.01.013

6. Roberts E, Delgado Nunes V, Buckner S, Latchem S, Constanti M, Miller P et al (2016) Paracetamol: not as safe as we thought? A systematic literature review of observational studies. Ann Rheum Dis 75(3):552-559. https://doi.org/10.1136/annrheumdis-2014206914

7. Gulmez SE, Larrey D, Pageaux GP, Bernuau J, Bissoli F, Horsmans Y et al (2015) Liver transplant associated with paracetamol overdose: results from the seven-country SALT study. Br J Clin Pharmacol 80(3):599-606. https://doi.org/10.1111/bcp.12635

8. Bruyere O, Cooper C, Al-Daghri NM, Dennison EM, Rizzoli R, Reginster JY (2017) Inappropriate claims from non-equivalent medications in osteoarthritis: a position paper endorsed by the European Society for Clinical and Economic Aspects of Osteoporosis, Osteoarthritis and Musculoskeletal Diseases (ESCEO). Aging Clin Exp Res 30(2):111-117. https://doi.org/10.1007/s4052 0-017-0861-1

9. Martel-Pelletier J, Farran A, Montell E, Verges J, Pelletier JP (2015) Discrepancies in composition and biological effects of different formulations of chondroitin sulfate. Molecules 20(3):42774289. https://doi.org/10.3390/molecules20034277

10. Kucharz EJ, Kovalenko V, Szanto S, Bruyere O, Cooper C, Reginster JY (2016) A review of glucosamine for knee osteoarthritis: why patented crystalline glucosamine sulfate should be differentiated from other glucosamines to maximize clinical outcomes. Curr Med Res Opin 32(6):997-1004. https://doi.org/10.1185/03007 995.2016.1154521

11. Towheed TE, Maxwell L, Anastassiades TP, Shea B, Houpt J, Robinson V et al (2009) Glucosamine therapy for treating osteoarthritis. Cochrane Database Syst Rev 2:CD002946. https://doi. org/10.1002/14651858.cd002946.pub2

12. Eriksen P, Bartels EM, Altman RD, Bliddal H, Juhl C, Christensen R (2014) Risk of bias and brand explain the observed inconsistency in trials on glucosamine for symptomatic relief of osteoarthritis: a meta-analysis of placebo-controlled trials. Arthritis Care Res (Hoboken) 66(12):1844-1855. https://doi.org/10.1002/ acr.22376

13. Runhaar J, Rozendaal RM, Middelkoop MV, Bijlsma HJW, Doherty M, Dziedzic KS et al (2017) Subgroup analyses of the effectiveness of oral glucosamine for knee and hip osteoarthritis: a systematic review and individual patient data meta-analysis from the OA trial bank. Ann Rheum Dis 76(11):1862-1869. https://doi. org/10.1136/annrheumdis-2017-211149

14. Reginster JL, Bruyere O, Cooper C (2017) Different glucosamine sulfate products generate different outcomes on osteoarthritis symptoms. Ann Rheum Dis. https://doi.org/10.1136/annrheumdi s-2017-212251

15. Reginster JY, Dudler J, Blicharski T, Pavelka K (2017) Pharmaceutical-grade chondroitin sulfate is as effective as celecoxib and superior to placebo in symptomatic knee osteoarthritis: the chondroitin versus celecoxib versus placebo trial (CONCEPT). Ann
Rheum Dis 76(9):1537-1543. https://doi.org/10.1136/annrheumdi s-2016-210860

16. Honvo G, Reginster J-Y, Rabenda V, Geerinck A, Mkinsi O, Charles A et al (2019) Safety of symptomatic slow-acting drugs for osteoarthritis: outcomes of a systematic review and metaanalysis. Drugs Aging 36(Suppl 1):65-99. https://doi.org/10.1007/ s40266-019-00662-Z

17. Honvo G, Leclercq V, Geerinck A, Thomas T, Veronese N, Charles A et al (2019) Safety of topical non-steroidal anti-inflammatory drugs in osteoarthritis: outcomes of a systematic review and meta-analysis. Drugs Aging 36(Suppl 1):45-64. https://doi. org/10.1007/s40266-091-00661-0

18. Coxib and traditional NSAID Trialists' (CNT) Collaboration, Bhala N, Emberson J, Merhi A, Abramson S, Arber N et al (2013) Vascular and upper gastrointestinal effects of non-steroidal antiinflammatory drugs: Meta-analyses of individual participant data from randomised trials. Lancet 382(9894):769-779. https://doi. org/10.1016/s0140-6736(13)60900-9

19. Wang X, Tian HJ, Yang HK, Wanyan P, Peng YJ (2011) Metaanalysis: cyclooxygenase-2 inhibitors are no better than nonselective nonsteroidal anti-inflammatory drugs with proton pump inhibitors in regard to gastrointestinal adverse events in osteoarthritis and rheumatoid arthritis. Eur J Gastroenterol Hepatol 23(10):876-880. https://doi.org/10.1097/MEG.0b013e328349de8 1

20. Gunter BR, Butler KA, Wallace RL, Smith SM, Harirforoosh $S$ (2017) Non-steroidal anti-inflammatory drug-induced cardiovascular adverse events: a meta-analysis. J Clin Pharm Ther 42(1):27-38. https://doi.org/10.1111/jcpt.12484

21. Nissen SE, Yeomans ND, Solomon DH, Luscher TF, Libby P, Husni ME et al (2016) Cardiovascular safety of celecoxib, naproxen, or ibuprofen for arthritis. N Engl J Med 375(26):25192529. https://doi.org/10.1056/NEJMoa1611593

22. Bally M, Dendukuri N, Rich B, Nadeau L, Helin-Salmivaara A, Garbe E et al (2017) Risk of acute myocardial infarction with nsaids in real world use: bayesian meta-analysis of individual patient data. BMJ 357:j1909. https://doi.org/10.1136/bmj.j1909

23. Curtis E, Fuggle N, Shaw S, Spooner L, Ntani G, Parsons C et al (2019) Safety of cyclo-oxygenase-2 inhibitors in osteoarthritis: outcomes of a systematic review and meta-analysis. Drugs Aging 36(Suppl 1):25-44. https://doi.org/10.1007/s40266-40019-00664 $-\mathrm{x}$

24. Ungprasert P, Matteson EL, Thongprayoon C (2016) Nonaspirin nonsteroidal anti-inflammatory drugs and risk of hemorrhagic stroke: a systematic review and meta-analysis of observational studies. Stroke 47(2):356-364. https://doi.org/10.1161/STROK EAHA.115.011678

25. Ungprasert P, Cheungpasitporn W, Crowson CS, Matteson EL (2015) Individual non-steroidal anti-inflammatory drugs and risk of acute kidney injury: a systematic review and meta-analysis of observational studies. Eur J Intern Med 26(4):285-291. https:// doi.org/10.1016/j.ejim.2015.03.008

26. Zeng C, Dubreuil M, LaRochelle MR, Lu N, Wei J, Choi HK et al (2019) Association of tramadol with all-cause mortality among patients with osteoarthritis. J Am Med Assoc 321(10):969-982. https://doi.org/10.1001/jama.2019.1347

Publisher's Note Springer Nature remains neutral with regard to jurisdictional claims in published maps and institutional affiliations. 


\section{Affiliations}

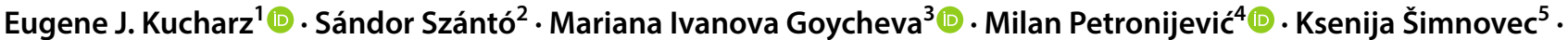

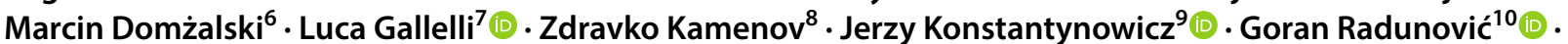

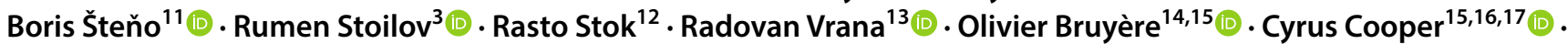 Jean-Yves Reginster ${ }^{14,15,18}$}

Eugene J. Kucharz

ejkucharz@poczta.onet.pl

Sándor Szántó

szanto.sandor@med.unideb.hu

Mariana Ivanova Goycheva

mariana_ig@abv.bg

Milan Petronijević

milanmandic69@gmail.com

Ksenija Šimnovec

ksenija.simnovec@sb-je.si

Marcin Domżalski

marcindomzalski@yahoo.com

Luca Gallelli

gallelli@unicz.it

Zdravko Kamenov

zkamenov@hotmail.com

Jerzy Konstantynowicz

jurekonstant@o2.pl

Goran Radunović

g.radunovic47@gmail.com

Boris Šteňo

boris.steno@fmed.uniba.sk

Rumen Stoilov

rmstoilov@abv.bg

Rasto Stok

rasto.stok@gmail.com

Radovan Vrana

vranaradovan@ seznam.cz

Olivier Bruyère

olivier.bruyere@uliege.be

Cyrus Cooper

cc@mrc.soton.ac.uk

1 Department of Internal Medicine, Rheumatology and Clinical Immunology, Medical University of Silesia, Katowice, Poland

2 Department of Sports Medicine, Faculty of Medicine, University of Debrecen, Debrecen, Hungary

3 Rheumatology Clinic, Medical Faculty, University Hospital "St. Iv. Rilski”, Medical University, Sofia, Bulgaria
4 Clinic of Rheumatology, MMA Medical Faculty, University of Defence, Military Medical Academy, Belgrade, Serbia

5 Department of Orthopedics, General Hospital Jesenice, Jesenice, Slovenia

6 Orthopedic and Trauma Department Medical, Veteran's Memorial Hospital, University of Lodz, Lodz, Poland

7 Clinical Pharmacology and Pharmacovigilance Operative Unit, Department of Health Sciences, MaterDomini Hospital Catanzaro, University of Magna Graecia Catanzaro, Catanzaro, Italy

8 Department of Internal Medicine, Clinic of Endocrinology, Medical University Sofia, University Hospital "Alexandrovska", Sofia, Bulgaria

9 Department of Pediatric Rheumatology, Immunology, and Metabolic Bone Diseases, Medical University of Bialystok, Bialystok, Poland

10 Institute of Rheumatology, University of Belgrade Medical School, Resavska 69, Belgrade, Serbia

11 II. Department of Orthopaedic and Trauma Surgery, Faculty of Medicine in Bratislava, Comenius University, University Hospital Bratislava, Bratislava, Slovakia

12 Ultramedica, Vošnjakova 1, Ljubljana, Slovenia

13 Osteocentrum Mediekos Ltd., Orthopedics, Ortopedie Hradiště Ltd., Uherské Hradiště, Czech Republic

14 Division of Public Health, Epidemiology and Health Economics, University of Liège, CHU Sart Tilman B23, 4000 Liege, Belgium

15 WHO Collaborating Centre for Public Health Aspects of Musculoskeletal Health and Aging, Liege, Belgium

16 MRC Lifecourse Epidemiology Unit, Southampton General Hospital, University of Southampton, Southampton, UK

17 National Institute for Health Research (NIHR) Musculoskeletal Biomedical Research Unit, University of Oxford, Oxford, UK

18 Chair for Biomarkers of Chronic Diseases, Biochemistry Department, College of Science, King Saud University, Riyadh, Kingdom of Saudi Arabia 